\title{
Antipsychotic Drugs Opposite to Metabolic Risk: Neurotransmitters, Neurohormonal and Pharmacogenetic Mechanisms Underlying with Weight Gain and Metabolic Syndrome
}

\author{
Walter Milano*, ${ }^{*}$, Michele De Rosa ${ }^{1}$, Luca Milano ${ }^{1}$ and Anna Capasso ${ }^{2}$ \\ ${ }^{1}$ Mental Health Unit- District 24 - ASL Napoli 1 Center, Italy \\ ${ }^{2}$ Department of Pharmacy, University of Salerno, Italy
}

\begin{abstract}
Important sources of metabolic diseases such as obesity and metabolic syndrome are significantly more prevalent in patients treated with antipsychotic drugs than the general population and they not only reduce the quality of life but also significantly reduce the life expectancy, being important risk factors for cardiovascular disease. The pathogenic mechanisms underlying these events are not entirely clear they are complex and multi-determined or not tied to a single defining event.

In this review we examine the literature on the interactions of antipsychotic drugs with neurotransmitters in the brain, with pharmacogenetics hormones and peripheral mechanisms that may induce, albeit in different ways between different molecules, not only weight gain but also 'onset of major diseases such as diabetes, dyslipidemia and hypertension that are the basis of the metabolic syndrome. Today, the possible metabolic changes induced by various antipsychotic drugs and their major physical health consequences, are among the major concerns of clinicians and it is therefore necessary to monitor the main metabolic parameters to prevent or minimize any of these patients as well as the metabolism events associated with the use of antipsychotic drugs.
\end{abstract}

Keywords: Antipsychotic drugs, metabolic risk, weight gain.

\section{INTRODUCTION}

Antipsychotics (AP) are drugs commonly used in clinical practice in the treatment of psychosis and other serious mental illnesses in both adults and adolescents, because they have proven to be effective in controlling a wide spectrum of symptoms but they are often associated with the increase of 'appetite and weight gain", with an increased risk of developing diabetes and other important metabolic diseases.

Since the introduction in the late 60 s of last century, the first antipsychotics (first generation antipsychotic FGA), it was shown that these drugs could cause weight gain unquestionable because the event was, to some extent, obscured by the more frequent and impressive events related to extrapyramidal effects (EPS). Only in recent decades, with the prevalent use of atypical antipsychotics (second generation antipsychotic SGA), which have significantly reduced the incidence of EPS, weight gain and metabolic implications have led to greater attention by clinicians.

Overweight and obesity are beyond treatment, often in patients with schizophrenia or bipolar. It is estimated that patients with psychotic or other major mental illness, made a double incidence of obesity than the general population [1],

*Address correspondence to this author at the Mental Health Unit-District 24 - ASL Napoli 1 Center; Tel/Fax: +39-081-3473388458;

E-mail: wamilano@tin.it with a ratio of up to three times more intra-abdominal fat compared to age, gender and lifestyles [2]. In addition, patients with schizophrenia have an increased risk for the onset of complications related to obesity, not only for possible genetic link between the two diseases, but also for the presence, often, altered lifestyles is not correct, smoking, alcohol abuse, sedentary lifestyle, etc..) [3]. Among the metabolic alterations potentially induced by the AP weight gain is usually but not always, the first manifestation and can lead to obesity in short time, which often is associated with dyslipidemia, glucose intolerance and type 2 diabetes later. The cardiovascular complications associated with these changes help to increase the incidence of death from cardiovascular disease and reducing life expectancy among patients with severe mental illness. Some recent epidemiological work found that schizophrenic patients have a mortality risk of up to 2.5 times higher than the general population, matched by age and sex [4,5], with a 'life expectancy to about $20 \%$ in less [6]. Cardiovascular diseases are responsible for more than $50 \%$ of mortality in the population with schizophrenia [7].

To date, the possible metabolic changes induced by various AP drugs and their important consequences, are among the major concerns of clinicians in the practice of psychopharmacological therapy. 


\section{WEIGHT GAIN}

Overweight and obesity are clinical conditions that involve an increase in body fat and are currently classified by assessing body mass index (body mass index, BMI). The BMI is a factor that involves not only the variable weight but intersects with variable height. In this way you get a big advantage, because with only one value, you can express two different variables. The BMI is calculated by dividing weight in kilograms with the square of height in meters $\left(\mathrm{kg} / \mathrm{m}^{2}\right)$. BMI between 18.5 and 24.9 are indicative of normal, between 25 and 29.9 are indicative of overweight and over 30 shows obesity [4]

The condition of overweight, especially obesity, significantly reduces life expectancy because it is associated with major diseases, both physical and psychological. Obesity increases the risk of developing diabetes, arthritis, respiratory diseases, cancer, metabolic syndrome, stroke and cardiovascular disease [5]. Obesity, especially the increase in visceral fat in the abdomen, was significantly associated with insulin resistance that causes abnormal glucose metabolism, increased triglycerides, increased low-density lipoprotein (LDL), hypertension, abnormal coagulation which, together, induce a marked increase in coronary risk $[6,7]$. Also, many evidences of the literature, shows that obesity is associated with depression (in the U.S. among obese women, the incidence of depression is considered to be around 35\%), decreased self-esteem, guilt, shame and increase the social stigma which, of course, reduces the perceived quality of life $[8,9]$.

The use of antipsychotic drugs, including SGA, can commonly cause weight gain, several studies have evaluated the 'incidence between 50 and $80 \%$ of patients [10], with a weight gain estimated at approximately $10 \%$ [10]. As the AP class of drugs is quite heterogeneous, the effects on weight gain is quite variable between different agents [11].

The Consensus Development Conference on antipsychotic Drugs and Obesity and Diabetes, comparing various evidences of the literature on the metabolic effects of the AP, found that clozapine and olanzapine are more closely linked to weight gain, followed by risperidone and quetiapine, and ziprasidone and aripiprazole may induce little or no weight gain [12].

A recent meta-analysis by Steven Leucht et al. [13] compared haloperidol, a FGA, with several SGA and found that clozapine, olanzapine and sertindole induced a greater increase in weight over $3 \mathrm{~kg}$ haloperidol.

The National Institute of Mental Health, in a large observational study, randomized controlled trial (CATIE), lasting 18 months, showed that patients treated with olanzapine had taken an average of $4.3 \mathrm{~kg}$, those treated with risperidone 0 , $36 \mathrm{~kg}, 0.50 \mathrm{~kg}$ while those patients treated with quetiapine and ziprasidone perphenazine had lost respectively 0.91 and $0.73 \mathrm{~kg}$ [14].

A significant factor in increasing susceptibility to weight gain induced by AP was found to be the onset of the disease. The European First Episode Schizophrenia Trial (EUFEST) [15], a study of schizophrenic patients over a year on the first episode of illness, showed a marked weight gain during treatment with AP. Olanzapine induced an increase of 13.9 $\mathrm{kg}, 10.5 \mathrm{~kg}$ of quetiapine, ziprasidone of $4.8 \mathrm{~kg}$ while the haloperidol of $7.3 \mathrm{~kg}$.

Significant weight gain was shown in another trial, randomized, double-blind, lasting about one year, first-episode patients treated with some of the most widely used EMS, the comparator of Atypical in First Episode of Psychosis ( CAFE ') [16]. Weight gain was assessed through a valid clinical indicator: weight gain of more than 7\% from baseline. With almost $80 \%$ of olanzapine-treated patients has exceeded $7 \%$ of initial weight compared with $58 \%$ of the risperidone group and $50 \%$ of the quetiapine group. Even a recent study [17] showed a marked weight gain in patients with a mean age of 27 years, drug-naive first-episode psychosis was treated with AP. On 128 patients treated with haloperidol, olanzapine and risperidone in 12 weeks of treatment, there was an average increase of $5.7 \mathrm{~kg}(3.8 \mathrm{~kg}$ with haloperidol, olanzapine $7.5 \mathrm{~kg}$ and $5.6 \mathrm{~kg}$ with risperidone).

The mechanism by which AP induces weight gain is complex and multi-determined, or are deemed to be necessary social conditions that contribute together, rather than a single triggering event.

Basically, the AP determined, through various mechanisms and then try to analyze in detail, increased appetite, and then the food-intake and a reduction, albeit modest, energy consumption [18].

Weight gain induced by AP could also show considerable individual variability, even in patients taking the same drug. Of course, the different lifestyles of individual patients is an important but not decisive by itself, several other conditions may become predisposing to weight gain.

Various clinical parameters can be used as possible predictors of weight gain. Among these may include the dosage and duration of treatment, the period of illness, age, sex, race, smoking, environmental factors, genetic factors and the deviation from normal (BMI) and premorbid before the beginning of treatment [19]. In fact, subjects with lower BMI tend to gain weight to a greater extent than patients who are already overweight or obese before treatment [20]. In addition, younger patients, especially women, the first psychotic episode, seems particularly vulnerable to increased APinduced weight gain [18-20] The use of other drugs (some mood stabilizers, antidepressants and benzodiazepine drugs among the general or common use of drugs such as steroids, estrogen progestin, antihistamines, etc.) in association with the AP was also associated with greater weight gain than the monotherapy [21]. Of course, the interactions between different molecules, doses used, the severity of underlying disease and comorbidities make complex issues and analysis of observed data.

Drug interactions of AP, are the levels of the central nervous system (hypothalamus and brain stem in particular) that in the suburbs, with some neurotransmitters, neuropeptides and hormones (eg insulin, ghrelin, leptin and other adipokines), determine an imbalance of the neuroendocrine network control energy homeostasis and body weight. 


\section{MECHANISMS OF ACTION OF AP ON NEURO- TRANSMITTERS}

The clinical effect of AP is manifested by modulating the action of neurotransmitters and interacting with their membrane receptors. Binding to dopamine D2 receptors (both antagonism of partial agonism) is at the time is essential for the effectiveness of antipsychotic and it is the only mechanism common to all AP approved by various international regulatory bodies. However, as we know, the AP is a very heterogeneous class of drugs with multiple actions on different receptors, such as serotonin, muscarinic, histaminergic and noradrenergic and with different degrees of affinity.

The receptors are those most associated with increased weight serotonin 2C (5-HT2C), histamine $1(\mathrm{H} 1)$ and $\mathrm{H} 3$ autoreceptors and also the D2 dopamine receptor, although little has been studied from this point of view. In fact, the blockade of D2 by the AP can alter energy metabolism, either by altering the signaling that reduce the physical activity [22]. The antagonism by the AP on all of these receptors at central level, causes a marked increase in food-intake through an increase in appetite and reduced ability to perceive the feeling of satiety [11,12].

Studies in animal models, mice knocked out for 5HT2C receptor gene, have provided interesting results because they simulated the effect of pharmacological blockade of these receptors resulting in these animals a state of hyperphagia, which further results in obesity and chronic hyperinsulinemia [23].

Furthermore, the antagonistic action of AP on $\mathrm{H} 1$ and $\mathrm{H} 3$ receptors are present on the arcuate and paraventricular nuclei of the hypothalamus. The mediated activation of second messenger adenosine monophosphate kinase (AMPK), not only increases the appetite by stimulating the streets orexigene through the 'activation of age-related protein (AgRP), but also by inhibiting the ability of the anorexigenic leptin in the hypothalamus $[12,13,20]$. To control the complex mechanism, other receptors appear to be involved, albeit to a small extent, such as alpha-adrenergic receptor $1 \alpha$ [21] and sterol regulatory element binding protein (SREBP).

The SREBP transcription factors are important regulators for cell biosynthesis of cholesterol and triglycerides. Both the SGA and FGA seem to activate the system of SREBPcontrolled lipogenesis in human hepatocytes [13, 24]. Although muscarinic receptors 3 (M3) are involved in increasing weight gain induced by AP, albeit indirectly. In fact, the blockade of M3 receptors in the pancreatic beta cell, mostly due to the SGA, induces alterations in glucose metabolism due to reduction in insulin secretion and increased insulin resistance $[25,26]$. The different receptor profiles of the various AP account for the different skills that individuals possess AP drugs induce weight gain. Both clozapine to olanzapine, more drugs involved in increasing the weight, are characterized by a higher affinity for $\mathrm{H} 1$ receptors and 5HT2C. Risperidone, which has a lower affinity for H1 receptors and 5-HT2C, is less involved in inducing weight gain. Ziprasidone, conversely, is a potent 5-HT1A receptor agonist and 5-HT2C receptor antagonist and a modest effect on weight may be interpreted through the inhibition at the synaptic re-uptake of serotonin and norepinephrine [14]. Aripiprazole, however, has a peculiar action of D2 receptor partial agonist and 5-HT1A. The essential neutrality of action on the weight is attributable to the modest affinity for $\mathrm{H} 1$ receptors and 5-HT2C [15].

\section{NEUROHORMONAL MECHANISMS OF ACTION OF THE AP}

Many studies have shown that the AP, in particular SGA, more strongly implicated in increasing weight, can cause alterations of the neuroendocrine network that controls appetite, food-intake and the perception of satiety. The data in the literature, at the time, show a predominant involvement of insulin, leptin, adiponectin, orexin, ghrelin and prolactin.

\section{Insulin}

It has long been known as the evidence of abnormal carbohydrate metabolism in patients with schizophrenia, regardless of use of AP drugs. Careless lifestyles, often in these patients, such as smoking, low physical activity, nutrition unfairly, etc. may promote abnormal glucose metabolism. Recent research has shown that the very presence of schizophrenia may contribute to the onset of decreased sensitivity to insulin. In a large cohort of first-episode schizophrenic patients, drug-naive, compared with a control group, was detected not only a higher prevalence of impaired glucose tolerance (IGT), but also significant differences between patients and controls for the levels of insulin, both fasting and two hours after oral glucose load [26]. In other studies $[27,28]$, patients in the first episode and drug-naive, showed alterations in insulin levels and glucose metabolism.

In addition, several studies have found that the AP pharmacoepidemiology, both first-and second-generation, interfere with the release and biological function of insulin, favoring the emergence of not only alterations of carbohydrate metabolism but also the regulation of food control [29].

Insulin, protein hormone secreted by beta cells of the islets of Langerhans in the pancreas, is a key hormone in regulating metabolism and energy, acting, in fact, not only on carbohydrate metabolism but also on the proteins and lipids. For all mammals, including humans, insulin is the main anabolic hormone because all the energy accumulation process Members are subject to its regulation.

The insulin-binding receptor on the membrane of target cells give off a cascading series of reactions, starting from the cell membrane and involve the entire cell. Such reactions invest the metabolism of all major food components (carbohydrates, lipids and proteins), electrolyte (sodium and potassium) and enzymatic organism, with the final effect of reducing the concentrations in the blood compartment in favor of the intracellular. Insulin acts on carbohydrate metabolism by facilitating the passage of glucose from the blood to cells and thus has a potent hypoglycemic action, favoring the accumulation of glucose as glycogen (glycogen) in the liver and blocking the breakdown of glycogen to glucose (glycogenolysis). On protein metabolism, insulin promotes the passage of amino acids from the blood cells by stimulating protein synthesis and inhibiting neoglucogenesis (formation of 
glucose from certain amino acids) [30]. Finally, acting on lipid metabolism favoring the passage of fatty acids into cells, insulin stimulates the synthesis of fatty acids from glucose and amino acid in excess and inhibits lipolysis by stimulating lipoprotein lipase (LPL) and hormone-inhibiting lipase sensitive (HSL) and therefore, in conclusion, would support the use of fatty acids for energy. In addition, the interaction between 'insulin and leptin can modulate, at the central level, the signals from the periphery of energy storage, affecting the food-intake [31].

AP drugs have the potential to interfere with the function of 'insulin, not only indirectly by interacting with various neurotransmitters involved in the regulation of carbohydrate metabolism but also through a direct action on pancreatic beta cells and the production of insulin [32-34], with increased adiposity, hepatic insulin resistance with consequent reduction of hepatic gluconeogenesis which is the main source of endogenous glucose production and, finally, beta cell dysfunction. Insulin resistance is the condition in which exposure to a given amount of insulin, which is structurally and functionally normal, evokes a biological response to the expectation of less. Insulin resistance in various trials, coupled with the use of AP drugs during treatment for schizophrenia. The hyperinsulinemia may be considered as the expression of insulin in plasma.

It is interesting to note that some SGA, such as olanzapine and clozapine, can induce insulin resistance irrespective of their effects on weight gain. In particular, in patients treated with olanzapine was found a marked insulin resistance than non-psychiatric controls and those treated with risperidone and FGA, regardless of BMI [35-36]. Insulin resistance, the centrality of the body anabolic effect of insulin on mechanisms, is not only associated with alterations of glucose metabolism but also with increased levels of triglycerides (TG) plasma, reduced HDL cholesterol, increased blood pressure, increased clotting factors and inflammatory markers.

The overweight and obesity can increase insulin resistance.

\section{Leptin}

Leptin is a protein hormone synthesized by adipocytes of adipose tissue and is one of the main hormones involved in the regulation of energetic input. Leptin, after being released into the bloodstream, passes the blood-brain barrier and binds to specific receptors in the ventral medial nucleus (VMN) of the hypothalamus. Binding to neurons in the VMN leptin signals the brain that the energy level stored in adipose tissue is sufficient, and then induces the subjective feeling of satiety. This mechanism is mediated through inhibition of the neuropeptide Y (NPY), which is the most powerful orexigen in the brain and also has an effect of leptin on regulation against it. Leptin is also directly related to the regulation of insulin and glucose, and is involved in the control of 'insulin-sensitivity [23,25]. Some studies have shown that the use of AP significantly increases blood levels of leptin [31-37]). In addition, recent studies have shown a direct effect of leptin on dopamine neurons in the ventral- segmental area (VTA) [38]. The increase of leptin appears to be a consequence rather than a cause of weight gain induced by AP. Thus, presumably leptin plays an important role in keeping the weight gain rather than being the primary cause. Furthermore, it was also reported that the AP can promote a state of leptin resistance [39] which, similarly to insulin resistance, a condition that would cause an inadequate response to mechanisms of biological control food intake. Also, leptin is involved in the regulation of body fat distribution and, therefore, the use of AP, involving the regulation of leptin signaling would promote the increase of the deposition of visceral fat [30]. Probably, there are genetic variants of the receptor for leptin, which may predispose individual patients to treatment with AP, which results in increase weight gain [24-32].

\section{Adiponectin}

Adiponectin is a circulating peptide released by adipocytes and has anti-inflammatory and antiatherogenic properties and is involved in regulating fat oxidation in lipid metabolism and improving insulin sensitivity [40]. The insulinsensitizing effect of adiponectin is mediated by an increase in fatty acid oxidation, decreased hepatic glucose production, increased 'uptake of glucose by enhancing insulin signaling by stimulating the Insulin Receptor Substrate 1 (IRS-1 ), which transduces the insulin signal to multiple cellular effectors [41]. Recent data $[42,43]$ seem to indicate thatAP, in particular olanzapine, reduce the production of adiponectin and thus its protective function, either indirectly by promoting weight gain or directly by interacting metabolism adiponectin by adipocytes.

\section{Ghrelin}

Ghrelin is a polypeptide hormone produced by the cells of the fundus of the stomach that interacts with neurons in the arcuate nucleus, and ventromedial hypothalamus stimulates appetite in significantly reducing the fat and facilitates the oxidation of fatty acids. It also plays an active role in the homeostasis of sugars and insulin secretion, with a negative feedback mechanism. Ghrelin levels rose before meals and decrease after about an hour and seen as complementary to leptin, so much so that the circulating blood levels of ghrelin correlated negatively with leptin and BMI.

In addition, ghrelin potency stimulates the secretion of growth hormone from anterior pituitary [44].

The currently available data are still conflicting but are moving decisively towards the hypothesis that AP drugs, in particular SGA olanzapine, stimulate the release of ghrelin, and not only its effect orexizant but also, simultaneously, its ability to inhibit the anorectic pathways at the central level $[25,26,31,32]$.

A small number of neurons located in the lateral hypothalamic / perifornical and member of the production and release of a peptide called orexin that is positively involved in the regulation of body weight control. The AP further involved in inducing weight gain appear to activate these neurons by stimulating the release of orexin [45] and hence increase appetite. 


\section{Prolactin}

Among the hormones involved in increasing farm hyperprolactinemia induced by the AP also plays an important role. The increase in circulating levels of prolactin alters the sensitivity and insulin-induced hypogonadism that increases adiposity [41].

\section{PHARMACOGENETIC}

It is of common evidence in clinical practice, which in some patients are more susceptible than others to gain weight during treatment with AP. In some patients, in fact, weight gain may begin after a few rounds of initiation of therapy and is irreversible, even after reducing the dose or switching to other drugs. This finding underlines the hypothesis of a genetic susceptibility factor that favors the clinical expression of AP-induced weight gain. Several studies have suggested that a single nucleotide polymorphism (SNP single nucleotide polymorphism) of 5-HT2C receptor (-759 T / C gene HTR2C) is associated with increased susceptibility to weight gain and metabolic syndrome induced by AP [33]. A meta-analysis of eight studies showed that patients treated with AP, carrying the $\mathrm{C}$ receptor $5 \mathrm{HT} 2 \mathrm{C}$ had more than twice a risk of weight gain significantly $(\geq 7 \%$ of initial weight) than carriers of allele $T$ [46]). Some studies $([47,48]$ on a large cohort of the population, have linked obesity to carry the $\mathrm{C}$ also present in the general population and therefore the use of AP, in carriers of this polymorphism, can speed up or increase the ' weight gain, which tends to have favor this change in gene expression. It has also been suggested that the polymorphism of 5-HT2C receptor induces a reduction of the anorectic effect of leptin in the hypothalamus [34].

In addition, other recent works have shown that polymorphisms transporter serotonin (SERT), such as the presence of the short allele, are associated with weight gain induced by olanzapine which is significantly higher compared with control patients [35]. In addition to these there are several candidate genes to increase susceptibility to the increase in metabolic diseases favored by treatment with AP and the current genomic studies of the drug have estimated them around 300 genes [36].

The results of linkage studies and genome-wide affect specific genes, such as the promelanin concentrating hor- mone $(\mathrm{PMCH})$, the polycystic kidney and hepatic disease 1 (PKHD1), the peptidylglycine $\alpha$-amidating monooxygenase (PAM) and endocannabinoid receptors. Others include the $\alpha 2 \mathrm{a}$ adrenergic receptor gene (ADR $\alpha 2 \mathrm{a})$, for leptin, ghrelin, for TNF to adiponectin, for the G protein and the D2 receptor $[13,36-38\rceil$. In a recent study was found a significant relationship between the polymorphism (DRD2-141C Ins / Del) for the section that affects the gene transcription of the dopamine D2 receptor and weight gain induced by AP [49].

Patients treated with AP (randomized between risperidone and olanzapine), carriers of the DRD2 Del, i.e. without nucleotide in that position, compared with patients homozygous instead of Ins / Ins, presented a weight gain of about 6 pounds at six weeks and about 15 pounds at the sixteenth week of observation.

In addition, a single nucleotide polymorphism of the adrenergic receptor gene (ADRA1A), is implicated in increased vulnerability increased AP-induced weight gain, particularly in young women (40). Some gene variants appear to be involved in metabolic drug-induced AP, as MEIS2 a polymorphism that increases abdominal circumference, which is one of the most significant indicators for intraabdominal adiposity [50]. Conversely, a polymorphism of the cannabinoid receptor (CNR1 rs806378) was associated with a particular resistance to weight gain induced by AP. Patients carrying this allele gained about $2.2 \mathrm{~kg}$ less during treatment with clozapine or olanzapine compared to patients who are non-carriers [39].

\section{METABOLIC SYNDROME}

The metabolic syndrome (MS) is defined as a constellation of interrelated risk factors, which confers an increased risk for the development of stable hypertension, diabetes mellitus type 2 and cardiovascular diseases. The criteria for the MS diagnosis include a number of factors such as high blood glucose, atherogenic dyslipidemia, characterized by substantial levels of triglycerides and low HDL cholesterol levels which tends upward of systolic and diastolic blood pressure and abdominal obesity [51]. The increase of fat deposited in the abdomen is an important risk factor for obesity-related diseases. The measurement of waist circumference (waist circunference: WC), with values greater than 102 $\mathrm{cm}$ and $88 \mathrm{~cm}$ in males and females, significantly correlated

Table 1. Diagnostic Criteria for Metabolic Syndrome

\begin{tabular}{|c|c|c|c|}
\hline & $\begin{array}{c}\text { ATP III } \\
\text { (3 Out of 5 Criteria Required) }\end{array}$ & $\begin{array}{c}\text { ATP III A } \\
\text { (3 Out of 5 Criteria Required) }\end{array}$ & $\begin{array}{c}\text { IDF } \\
\text { (Waist Plus 2 Criteria Required) }\end{array}$ \\
\hline \hline Waist $(\mathrm{cm})$ & $\mathrm{M}>102, \mathrm{~F}>88$ & $\mathrm{M}>102, \mathrm{~F}>88$ & $\mathrm{M} \geq 94, \mathrm{~F} \geq 80$ \\
\hline Blood Pressure & $\geq 130 / 85^{*}$ & $\geq 130 / 85^{*}$ & $\geq 130 / 85^{*}$ \\
\hline $\mathrm{HDL}(\mathrm{mg} / \mathrm{dl})$ & $\mathrm{M}<40, \mathrm{~F}<50$ & $\mathrm{M}<40, \mathrm{~F}<50$ & $\geq 150$ \\
\hline $\begin{array}{c}\text { Triglycerides } \\
(\geq 150 \mathrm{mg} / \mathrm{dl})\end{array}$ & $\geq 150$ & $\geq 150$ & $\geq 1000$ \\
\hline Glucose $(\mathrm{mg} / \mathrm{dl})$ & $\geq 100$ & $\geq 100$ & $\geq 100$ \\
\hline
\end{tabular}

ATP-Adult Treatment Protocol; IDF International Diabetes Federation

*or treated with antihypertensive medication; or treated with insulin or hypoglycemic medication 
with increased cardiovascular risk [52-54]. Individuals with MS also have clinical and biochemical changes, as with prothrombotic and pro-inflammatory [46].

The criteria, defined and internationally accepted standards for the diagnosis of metabolic syndrome are summarized in Table $\mathbf{1}$.

The values most widely used are those proposed by the Adult Treatment Panel III of National Cholesterol Education Program (ATP - NCEP III) in 2001 and revised in 2003 [43].

It is important to stress that it is not necessary that an order established a state of frank diabetes or obesity or a major dyslipidemia or hypertension net for the diagnosis of MS, but it is sufficient, as shown in the table, the presence, at the upper limits of normality, at least three of these clinical indices.

It is believed that three pathogenic mechanisms have a substantial role in determining the development of MS:

1) insulin resistance (or low insulin sensitivity) or the medical condition in which insulin exerts a biological effect of lower than expected;

2) the accumulated fat, especially visceral, with its functional disorder of adipose tissue, with a change in the production of hormones released by adipocytes, called adipokines (leptin, adiponectin, TNF, IL1, IL 6, apolipoprotein E, angiotensinogen, PAI-1, etc..), which strongly influence the glucose and lipid metabolism;

3 ) the production of a number of factors from the liver, vascular and immunological [44].

The increase in free fatty acids (FFA) in the circulation, secondary to an alteration of lipid metabolism plays an important role in the pathogenesis of insulin resistance through a specific blocking action on the signal transduction of insulin. In addition, increased blood concentrations of FFA, promotes oxidative stress, inflammatory status and an alteration of vascular reactivity that further contribute to insulin resistance [55].

MS is a disease quite common in the general population and the prevalence varies according to BMI, age, gender and ethnicity. Population studies [56], based on the Third National Health and Nutrition Examination Survey (NHANES III), the United States has assessed its impact on the whole about $22 \%$ of the general population and over $60 \%$ in the obese population (BMI> 30). In Europe and in Italy the incidence of MS is slightly lower. MS is considered to be the most common cardiovascular risk factor in the Western world and in many developing countries, in fact, it is characterized by the simultaneous presence of several risk factors that directly contribute to the development of 'atherothrombosis and is associated with twice the risk for cardiovascular events and up to 5 times higher for developing type 2 diabetes. Moreover, this risk increases progressively and linear in relation to the number of elements that characterize the SM present in the individual patient $[7,45,57])$. The association between severe mental illness such as schizophrenia and bipolar disorder, with the onset of MS is largely known for several years, but some recent reviews have clearly shown, this association [54, 58-60].
De Hert et al. [47], in a review of 38 studies published between 2003 and 2008 showed that the incidence of MS is two to three times higher in schizophrenic patients than the general population.

Meyer and Stahl [48], in a review of 11 studies reported not only a significant presence of MS in patients with chronic schizophrenia but also that the MS has an earlier onset in patients with schizophrenia than the general population.

In addition, in the study by CATIE [49], about a third of the patients had observed the criteria for MS at baseline. In a recent trial [50] schizophrenic patients followed up between 2000 and 2006, treated with SGA, were compared with schizophrenic patients followed between 1984 and 1995, treated with FGA, and it was found that the incidence of MS SGA, $27.8 \%$ vs $9.8 \%$ was significantly higher.

Finally, several studies $[51,52]$ have shown that children and adolescents treated with AP, are at increased risk of developing MS and weight gain, compared to adult patients who are taking the same drugs. Of course the use of AP drugs, not only causes weight gain, visceral adiposity but also promotes the incidence of MS in these patients. Recently [30] significantly increased adiposity, both subcutaneous and intra-abdominal, as assessed by MRI in a group of drug-naive schizophrenic patients, followed for 10 weeks treatment with AP was reported.

However, in approximately $25 \%$ of patients treated with AP, without weight gain or marked visceral adiposity, MS was present, suggesting a direct link between the metabolic action of drugs AP and the presence of SM [53].

\section{CONCLUSION}

Many psychoactive drugs are able to induce weight gain and are capable of inducing significant metabolic diseases. APs are certainly in this respect, the drugs most involved and most studied.

Overall, the data collected from the international literature, especially in the last decade, suggest that metabolic abnormalities in patients with severe mental illness and thus increase the risk of developing cardiovascular disease associated with it, which is linked to a number of concomitant risk factors, such as: an individual's genetic vulnerability, the very presence of underlying psychiatric illness etc., to assume genetic links; incorrect lifestyles and not the least, the use of drugs such as AP. Despite much research, carried on acute shortage of patients, the mechanisms underlying these events are not yet entirely clear, even to the obvious complexity of these networks, linked to the substance for the survival of the species, such as control of 'feeding and energy balance. The key mechanisms appear to be related to alterations in the regulation of the perception of hunger / satiety and energy homeostasis, and involve both receptors in the hypothalamus, 2c 5HTC for serotonin, histamine $\mathrm{H} 1$, for endocannabinoids and dopamine transmission and alphaadrenergic, and hormones, neuropeptides and their receptors that control airway and peripheral orexigene and anorexigenic. Moreover, the presence of several polymorphisms and some genes that control the synthesis of certain receptors or 
Table 2. Screening Metabolic Parameters in Patients Treatmennt with Antipsychotic

\begin{tabular}{|c|c|c|c|c|c|c|}
\hline & Basal & $1^{\circ}$ Month & $2^{\circ}$ Month & $3^{\circ}$ Month & Each 3 Month & Each Year \\
\hline Medical History* & $\mathrm{X}$ & & & & & \\
\hline $\mathrm{BMI}^{\circ}$ & $\mathrm{X}$ & $\mathrm{X}$ & $\mathrm{X}$ & $\mathrm{X}$ & $\mathrm{X}$ & \\
\hline Waist & $\mathrm{X}$ & & & $\mathrm{X}$ & $\mathrm{X}$ & \\
\hline Glucose & $\mathrm{X}$ & & & $\mathrm{X}$ & $\mathrm{X}$ & \\
\hline HDL & $\mathrm{X}$ & & & $\mathrm{X}$ & & $\mathrm{X}$ \\
\hline Tryglycerides & $\mathrm{X}$ & & & $\mathrm{X}$ & $\mathrm{X}$ & $\mathrm{X}$ \\
\hline Prolactin & $\mathrm{X}$ & $\mathrm{X}$ & & $\mathrm{X}$ & $\mathrm{X}$ & \\
\hline TSH FT4 & $\mathrm{X}$ & & & & & $\mathrm{X}$ \\
\hline Blood Pressure & $\mathrm{X}$ & & $\mathrm{X}$ & $\mathrm{X}$ & $\mathrm{X}$ & \\
\hline $\mathrm{ECG}^{\circ \circ}$ & $\mathrm{X}$ & & & & $\mathrm{X}$ & \\
\hline Serum electrolytes $^{\wedge}$ & $\mathrm{X}$ & & $\mathrm{X}$ & $\mathrm{X}$ & $\mathrm{X}$ & \\
\hline
\end{tabular}

* Family Medical history for obesity, diabetes, obesity, hyperlipidemia, menstrual disorders, sexual dysfunction and heart disease

${ }^{\circ}$ Body Mass Index (weight in kg / height in meters squared)

$\circ$ ECG with specific timelines for the QTc interval

$\wedge$ Serum electrolytes: Sodemare, serum potassium, calcium, Cloremia

transporter, is associated with increased susceptibility to weight gain and metabolic syndrome.

Many studies, mostly of drug epidemiology and genomic medicine will be needed in the near future to differentiate even more specifically between the drugs ability to induce metabolic changes and especially to evaluate the influence on the individual patient in the treatment of certain confounding variables, such as family history and personal experience for cardiovascular and metabolic diseases, lifestyle, type and stage of basic psychiatric illness, the use of previous treatments, comorbid somatic and mental el 'presence of several treatments.

In conclusion, all the AP, with a prevalence of SGA on FGA, can increase metabolism and thus the cardiovascular risk , and therefore it is necessary that clinicians should always take into account these possible adverse effects of treatment. Therefore, to maintain physical health it is also necessary to monitor metabolic parameters (Table 2) in all patients treated with the AP, even in the absence of marked overweight or obesity; encourage and support patients adopt healthy life styles and a healthier eating, or use psychoeducational interventions, including medication, if necessary, to minimize the metabolic events related to the use of AP. Threfore, it is recommanded to select the drug when the patient's clinical condition permits, the AP with the least impact on drug metabolism and, finally, consider the physical health of patients with mental illness as an integral part of patient care, actively collaborating with other health care facilities, such as primary care and specialist.

\section{CONFLICT OF INTEREST}

The authors confirm that this article content has no conflicts of interest.

\section{ACKNOWLEDGEMENT}

None Declared.

\section{REFERENCES}

[1] Dickerson FB, Brown CH, Kreyenbulh JA. Obesity among individuals with serious mental llness. Acta Psychiatr Scand 2006; 113 (4): 306-13.

[2] Ryan MC, Flanagan S, Kinsella U. Atypical antipsychotics and visceral fat distribution in first episode, drug-naïve patients with schizophrenia. Life Sci 2008; 74:1999-2008.

[3] Connolly M, Kelly C. Lifestyle and physical health in schizophrenia. Adv Psychiatr Treat 2005; 11:125-32.

[4] WHO. Obesity: preventing and managing the global epidemic. 2000; WHO Technical Report Series, number 894, Geneva: WHO 2000

[5] Haslam DW, James WPT. Obesity. Lancet 2005; 366:1197-209.

[6] Kenchaiah S, Gaziano JM, Vasan RS. Impact of obesity on the risk of heart failure and survival after onset of heart failure. Med Clin North Am 2004; 88: 1273-94.

[7] Lakka HM, Laaksonen DE, Lakka TA. The metabolic syndrome and total and cardiovascular disease mortality in middle-aged men. JAMA 2002; 288: 2709-16.

[8] Herva A, Laitinen J, Miettunen J. Obesity and depression. Int J Obes 2006; 30:520-7.

[9] Puhl RM, Henderson KE, Bronwell KD. Social consequences of obesity. In: Kopelman PG, Catergon ID, Dietz WH, Eds Clinical obesity. $2^{\text {nd }}$ ed. Oxford: Blackwell Publishing 2005; pp. 29-45.

[10] Reist C, Mintz J, Alberts L. Second-generation antipsychotic exposure and metabolic- related disorders in patients with schizophrenia: an observational pharmacoepidemiology study from 1988 to 2002. J Clin Psychopharmacol 2007; 27:46-51.

[11] Reynolds GP, Hill MJ, Kirk SL. The 5-HT2c receptor and antipsychotic induced weight gain: mechanism and genetics. J Psychopharmacol 2006; 20:15-8.

[12] Deng C, Weston-Geeen C, Huang XF. The role histaminergic H1 and $\mathrm{H} 3$ receptors in food-intake: a mechanism for atypical antipsychotic-induced weight gain ? Prog Neuropsychopharmacol Biol Psychiatry 2010; 34:1-4. 
[13] Rege S. Antipsychotic induced weight gain in schizophrenia: mechanism and management. Aust N Z J Psychiatry 2008; 42: 36981.

[14] Virk S, Schwartz TL, Jindal S. Psychiatric medication induced obesity: an aetiological review. Obes Rev 2004; 5:167-70.

[15] McQuade RD, Stock E, Marcus R. A comparasion of weight change during treatment with olanzapine or aripiprazole: results from a randomized, double-blind study. J Clin Psychiatry 2004; 65:47-56.

[16] Holt RI, Peveler RC. Obesity, serious mental illness and antipsychotic drugs. Diabetes Obes Metab 2009; 11: 665-79.

[17] Zinnerman U, Kraus T. Epidemiology, implications and mechanisms underlying drugs-induced weight gain in psychiatric patients. J Psychiatr Res 2003; 37:193-220.

[18] Alvarez-Jimenez M, Gonzales-Blanch C, Crespo-Facorro B. Antipsychotic-induced weight gain in chronic and first-episode psychotic disorders. A systematic critical reappraisal. CNS Drugs 2008; 22 (7): 547-62

[19] Gentile S. Contributing factors to weight gain during long-term treatment with second-generation antipsychotics. A systematic appraisal and clinical implications. Obes Rev 2009; 10:527-42.

[20] Han L, Deng C, Burne THJ. Short- and long- term effects of antipsychotics drugs treatment on weight gain and $\mathrm{H} 1$ receptor expression. Psychoneuroendocrinology 2008; 33: 569-80.

[21] Reynolds GP, Kirk SL Metabolic side effects of antipsychotic drug treatment - pharmacological mechanisms Pharm Ther 2010; 125: 169-79.

[22] Osborne DP, Levy G, Nazareth I. Relative risk of cardiovascular and cancer mortality in people with severe mental illness from the United Kingdom's general practice research database. Arch Gen Psychiatry 2007; 64 (2): 242-9.

[23] Meier U, Gressner AM Endocrine regulation of energy metabolism: review of phatobiochemical and clinical chemical aspects of leptin, ghrelin, adiponectin and resistin. Clin Chem 2004; 50 (9): 1511-25.

[24] Ellingrod VL; Bishop JR, Moline J. Leptin and leptin receptor gene polimorphisms and increase in body masss index from olanzapina treatment in persons with schizophrenia. Psychopharmacol Bull 2007; 40:57-62

[25] Popovic V, Doknic M, Marie N. Change in neuroendocrine and metabolic hormones induced by atypical antipsychotic in normalweight patients with schizophrenia. Neuroendocrinol 2007; 85: 249-56.

[26] Muraschita M, Kusumi I, Inoue T. Olanzapine increases plasma ghrelin level in patients with schizophrenia. Psychoneuroendocrinol 2005; 30: 106-10.

[27] Correll CU. Weight gain and metabolic effects of mood stabilazers and antipsychotics in pediatric bipolar disorder: a systematic review and pooled analysis of short-term trials. J Am Acad Child Adolesc Psychiatry. 2007; 46 (6): 687-700.

[28] Saha S, Chant D, McGrant J. A systematic review of mortality in schizophrenia: is the differential mortality gap worsening over time? Arch Gen Psychiatry 2007; 64 (10):1123-31.

[29] Correll CU, Malhorta AK. Pharmachogenetic of antipsychoticinduced weight gain. Psychopharmacol 2004; 174 (4): 477-89.

[30] Zhang ZJ, Yao ZJ, Liu W. Effects of antipsychotics on fat deposition and changes in leptin and insulin levels. Magnetic resonance imaging study of previously untreated people with schizophrenia. Br J Psychiatry 2004; 184: 58-62.

[31] Sentissi O, Epelbaum J, Oliè JP, Poirier MF. Leptin and ghrelin levels in patients with schizophrenia during different antipsychotics treatment: a review. Schizphr Bull 2008; 34 (6): 1189-99.

[32] Monteleone P, Fabrazzo M, Tortorella A, La Pia S, Maj M . Pronounced, early increase in circulating leptin predicts lower weight gain during clozapine treatment. J Clin Psychopharmacol 2002; 22: 424-6.

[33] Mulder H, Franke B.Van Der Beek AA. The association between HTR2c gene polymprphism and metabolic syndrome in patients with schizophrenia. J Clin Psychopharmacol 2007; 27: 238-343.

[34] Mandelli V, Pariante C. Metabolic syndrome and obesity in psychosis: the possible mechanisms. Obes metab 2008; 4: 59-64.
[35] Bozina N, Medved V, Kuzman MR. Association study of olanzapina-induced weight gain and therapeutic response with SERT gene polymorphism in female schizophrenic patients. J Psychopharmacol 2007; 21: 728-34.

[36] Chagnon YC. Susceptility genes for the side effects of antipsychotics on body weight and obesity. Curr Drug Targets 2006; 7: 168195.

[37] Muller DJ, Kennedy JL. Genetics of antipsychotic treatment emergent weight gain in schizophrenia. Pharmacogenomics 2006; 7: 863-87.

[38] Templeman LA, Reynold GP, Arranz B, San L. Polymorphism of 5-HT2c receptor and leptin genes are associated with antipsychotic drug-induced weight gain in Caucasian sujet with a first-episode psychosis. Pharmachogenet Genomics 2005; 15 (4):195-200.

[39] Tiwari AK, Zai CC, Likhodi O. A common polymorphism in the cannabinoid receptor 1 (CNR1) gene is associated with antipsychotic-induced weight gain in schizophrenia. Neuropsychopharmacology 2010; 35 (6): 1315-24.

[40] Liu YR, Loh EW, Lan TH. ADRA1A gene is associated with BMI in cronic schizophrenia patients exposed to antipsychotics. Pharmacogenomics J 2010; 10 (1): 30-9.

[41] Baptista T, Lacruz A, De Mendoza S. Body weight gain after administration of antipsychotic drugs: correlation with leptin, insulin and reproductive hormones. Pharmacopsychiatry 2000; 33: 81-8.

[42] Milano W, D'Acunto CW, Capasso A. Recent clinical aspects of hyperprolactinaemia induced by antipsycgotics. Rev Recent Clin Trials $2011 ; 6(1): 1-13$

[43] Expert panel on detection, evaluation and treatment of high blood cholesterol in adults. Executive summary of the third report of $\mathrm{Na}$ tional Cholesterol Education Program (NCEP) (Adult Treatment Panel III). JAMA 2001; 285: 2486-97.

[44] Alberti KG, Zimmer P, Shaw J. The IDF Epidemiology Task force Consensus Group. The Metabolic Syndrome: a new worldwide definition. Lancet 2005; 366:1059-62.

[45] Hanson RL, Imperatore G, Bennet PH, Knowlwr W. Components of metabolic syndrome and incidence of type 2 diabetes. Diabetes 2002; 51: 3120-7.

[46] Pramyothin P, Khaodhiar L .Metabolic syndrome with the atypical antipsychotics. Curr Opin Endocrinol Diabetes Obesity 2010; 17: 460-66.

[47] De Hert M, Schreurs V, Vancampfort D. Metabolic syndrome in people with schizophrenia: a review. World Psychiatry 2009; 8:1522.

[48] Meyer JM, Sthal SM. The metabolic syndrome and schizophrenia Acta Psychiatr Scand 2009; 119: 4-14.

[49] Patel JK, Buckley PF, Woolson S. Metabolic profiles of secondgeneration antipsychotic in early psychosis: findings from the CATIE study. Schizophr Res 2009; 111: 9-16.

[50] De Hert M, Hanssens L, Wampers M. Prevalence and incidence rates of metabolic abnormalities and diabetes in prospective study of patients treated with second-generation antipsychotics Schizphr Bull 2007; 33: 560-4.

[51] Correl CU. Assessing and maximizing the safety and tolerability of antipsychotics used in the treatment of children and adolescents. J Clin Psychiatry 2008; 69 (4):26-36.

[52] Kumra S, Oberstar JV, Sikich L. Efficacy and tolerability of second-generation antipsychotics in children and adolescents with schizophrenia. Schizophr Bull. 2008; 34:60-71.

[53] Newcomer JW. Second generation (atypical) antipsychotics and metabolic effects. A comprehensive literature review. CNS Drugs 2004; 19 (1): 1-93.

[54] Monteleone P, Martiadis V, Maj M. Management of schizophrenia with obesity, metabolic and endocrinological disorders. Psychiatr Clin N Am 2009; 32: 775-94.

[55] Dandona P, Aljada A, Chaudhuri A. Metabolic Syndrome: a comprehensive perspective based on interactions between obesity, diabetes and inflammation. Circulation. 2005; 111: 1448-54.

[56] Maayan L, Correll CU. Management of antipsychotic-related weight gain. Expert Rev Neurother 2010; 10 (7): 1175-200.

[57] American Diabetes Association; American Psychiatric Association; American Association of Clinical endocrinologists; North American Association for Study of Obesity. Consensus development con- 
ference on antipsychotic drugs and obesity and diabetes. J Clin Psychiatry 2004; 65(2): 267-72.

[58] Leucht S, Corves C, Arbter D. Second-generation versus firstgeneration antipsychotic drug for schizophrenia: a meta-analysis. Lancet. 2009; 373 (9657): 31-41.
[59] Lieberman JA, Stroup , McEvoj JP. Effectiveness of antipsychotic drugs on patients with chronic schizophrenia. N Engl J Med. 2005; 353:1209-23.

[60] McEvoj JP, Lieberman JA, Perkins DO. Efficacy and tolerability of olanzapina, quetiapine and risperidone in the treatment of early psychosis: a randomized, double-blind 52 weeck comparison. Am J Psychiatry 2007; 164: 1050-60.

(C) Milano et al.; Licensee Bentham Open.

This is an open access article licensed under the terms of the Creative Commons Attribution Non-Commercial License (http://creativecommons.org/licenses/by-nc/3.0/) which permits unrestricted, non-commercial use, distribution and reproduction in any medium, provided the work is properly cited. 